University of New Mexico

UNM Digital Repository

4-30-1974

\title{
Perturbation Analysis of Competition and Overlap in Habitat Utilization Between Dipodomys Ordii and Dipodomys Merriami
}

Gene D. Schroder

Follow this and additional works at: https://digitalrepository.unm.edu/biol_etds

Part of the Biology Commons

\section{Recommended Citation}

Schroder, Gene D.. "Perturbation Analysis of Competition and Overlap in Habitat Utilization Between Dipodomys Ordii and Dipodomys Merriami." (1974). https://digitalrepository.unm.edu/biol_etds/326

This Dissertation is brought to you for free and open access by the Electronic Theses and Dissertations at UNM Digital Repository. It has been accepted for inclusion in Biology ETDs by an authorized administrator of UNM Digital Repository. For more information, please contact amywinter@unm.edu. 
ERSITY OF NEW MEXICO-UNIVERSITY LUBRAAIES |||||||||||||||||||||||||||||

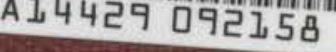

\section{논}

3781

N564Sh748

$\cos 2$ 

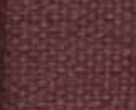

THE UNIVERSITY OF NEW MEXICO

ALBUQUERQUE, NEW MEXICO 87106

\section{Policy on Use of Theses and Dissertations}

Unpublished theses and dissertations accepted for master's and doctor's degrees and deposited in the University of New Mexico Library are open to the public for inspection and reference work. They are to be used only with due regard to the rights of the authors. The work of other authors should always be given full credit. Avoid quoting in amounts, over and beyond scholarly needs, such as might impair or destroy the property rights and financial benefits of another author.

To afford reasonable safeguards to authors, and consistent with the above principles, anyone quoting from theses and dissertations must observe the following conditions:

1. Direct quotations during the first two years after completion may be made only with the written permission of the author.

2. After a lapse of two years, theses and dissertations may be quoted without specific prior permission in works of original scholarship provided appropriate credit is given in the case of each quotation.

3. Quotations that are complete units in themselves (e.g., complete chapters or sections) in whatever form they may be reproduced and quotations of whatever length presented as primary material for their own sake (as in anthologies or books of readings) ALWAYS require consent of the authors.

4. The quoting author is responsible for determining "fair use" of material he uses.

This thesis/dissertation by Gene D. Schroder has been used by the following persons whose signatures attest their acceptance of the above conditions. (A library which borrows this thesis/dissertation for use by its patrons is expected to secure the signature of each user.)

NAME AND ADDRESS

DATE 

This dissertation, directed and approved by the candidate's committee, has been accepted by the Graduate Committee of The University of New Mexico in partial fulfillment of the requiremints for the degree of Doctor of Philosophy

PERTURBATION ANALYSIS OF COMPETITION AND

OVERLAP IN HABITAT UTILIZATION BETWEEN

Title
DIPODOMYS ORDII AND DIPODOMYS MERRIAM

Gene D. Schroeder

Candidate

Biology

Department

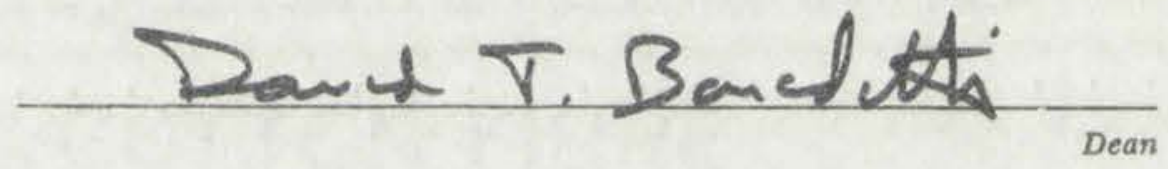

Committee
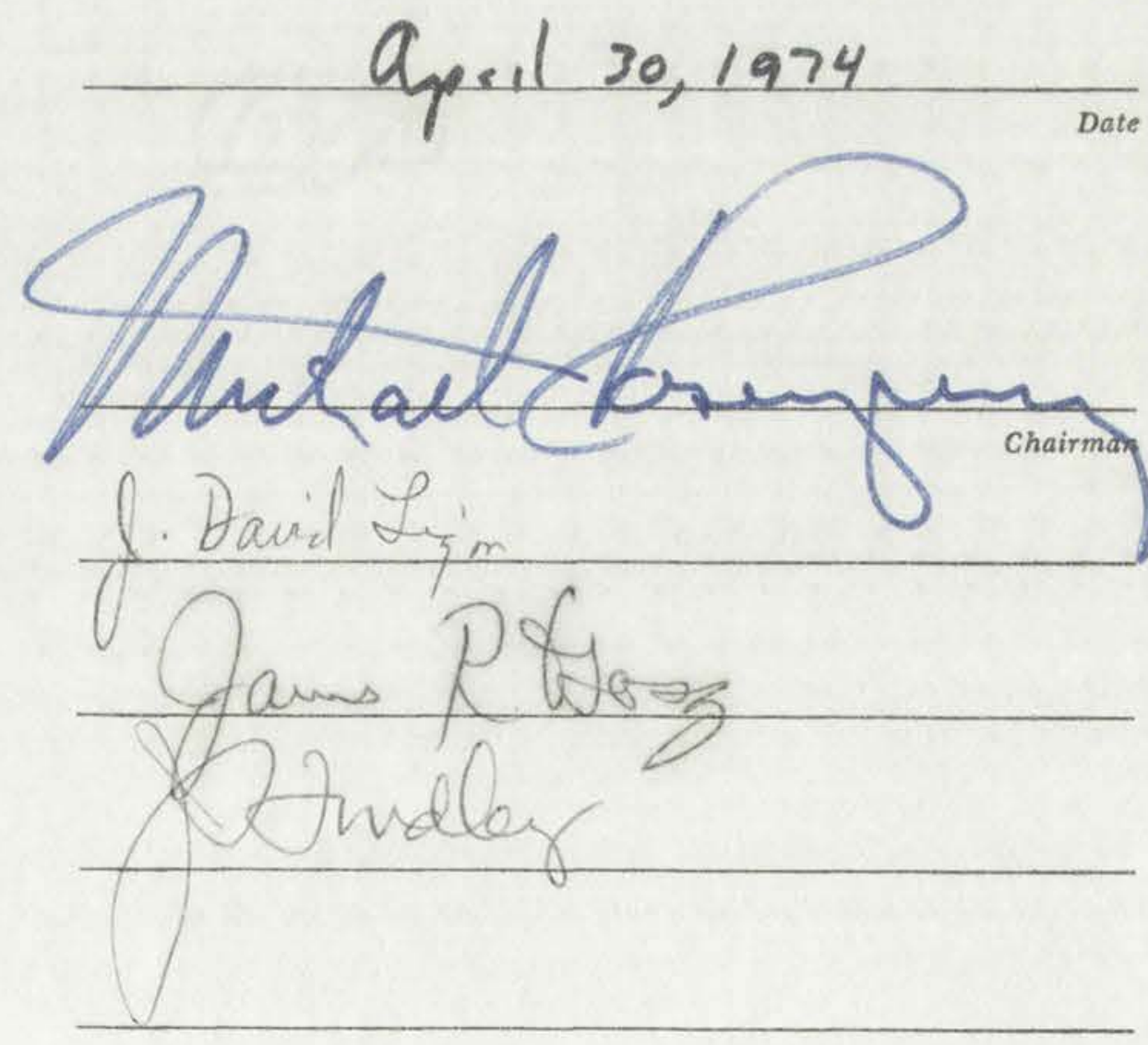

Gene D. By Schroder

\section{DISSERTATION}

Submitted in Partial Fulfillment of the

Requirements for the Degree of

Doctor of Philosophy in Biology

in the Graduate School of

The University of New Mexico

Albuquerque, New Mexico

$$
\text { May, } 1974
$$


I wish to thank my fellow students, Kenneth Geluso, Kim Mortensen, Curtis Hunt, and George White. Their helpful suggestions and willing assistance in the field made this work possible. The constructive criticism offered by Drs. J. David Ligon, James Findley, and James Gosz concerning this study is appreciated.

The inspiration, encouragement, field assistance, and critical evaluation provided by Dr. Michael Rosenzweig from the conception of the project to its completion are greatly appreciated.

My wife, Sherry, was my right hand in the field and an invaluable source of patience and encouragement throughout this project. I share with her the reward of satisfaction in its completion.

The Socorro, New Mexico office of the Bureau of Land Management kindly made available the land used in this study. This project was supported in part by NSF grant $\# \mathrm{~GB}-34804$. 

PERTURBATION ANALYSIS OF COMPETITION AND

OVERLAP IN HABITAT UTILIZATION BETWEEN

$\underline{\text { DIPODOMYS ORDII AND DIPODOMYS MERRIAMI }}$

Gene D. Schroder

\section{ABSTRACT OF DISSERTATION}

Submitted in Partial Fulfillment of the

Requirements for the Degree of

Doctor of Philosophy in Biology

in the Graduate School of

The University of New Mexico

Albuquerque, New Mexico

$$
\text { May, } 1974
$$


Perturbation Analysis of Competition and Overlap in Habitat Utilization Between Dipodonys ordii and Dipodomys merriami

Gene D. Schroder

Department of Biology

University of New Mexico, 1974

\section{ABSTRACT}

This study measures the magnitude of the competition between two nocturnal, desert rodents, Dipodomys ordii and D. merriami, on 10 unenclosed, 16 hectare plots along a narrow band of sympatry in south-central New Mexico. Population perturbations of one or the other species were periodically performed on eight of the plots, while natural population changes were monitored on two controls. The relative numerical responses of the kangaroo rats to these perturbations are thought to reflect the true magnitude of their competitive interaction.

Both species are strongly responsive to changes in their own densities, but are unresponsive or only weakly responsive to changes in the density of their presumed competitor. D. ordii demonstrated the existence of a large population of floating individuals by recruiting as many as three immigrants per day onto grids from which ords had been removed. Changes in D. merriami densities on ord's - perturbed plots did not differ from those on the control plots. Similar, but opposite, responses were measured on the plots from which D. nerriami were removed. These perturbations and others in which D. merriami were added to perturbed populations show no evidence of competition between these species. 

D. ordii rapidly extended its range in response to an unsuaul1y widespread occurrence of spring and summer grass, whereas, D. merriami were taken almost exclusively from shrubby habitats. This indicates that vegetation is very important in habitat selection, so I examined the distribution of these species and that of Perognathus flavus as a function of vegetation. Trapping records revealed that al1 three species prefer slightly different mixtures of creosote bush and grass, but the overlap in the range of habitats in which they are caught predicts very high competitive coefficients unless some other unmeasured variable should intervene. Using the trapping records and two techniques of alpha measurements, I estimated that alpha should be somewhere between .26 and .97. These estimates contradict the value of alpha shown to be near or equal to zero by the perturbation studies. This apparent contradiction is discussed, as is the role of habitat selection in controlling their interaction. 
TABLE OF CONTENTS

Page

ACKNOWLEDGEMENTS ..................... iii

ABSTRACT $\ldots \ldots \ldots \ldots \ldots \ldots \ldots \ldots \ldots \ldots \ldots \ldots \ldots \ldots \ldots \ldots \ldots \ldots \ldots$

LIST OF FIGURES ............................

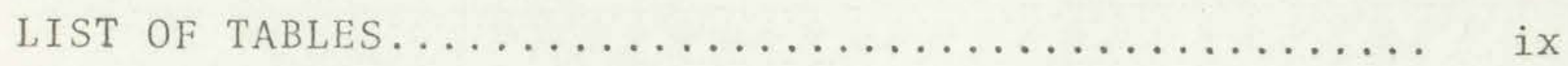

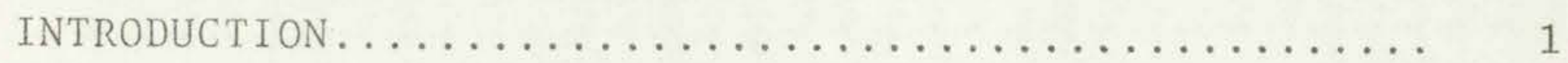

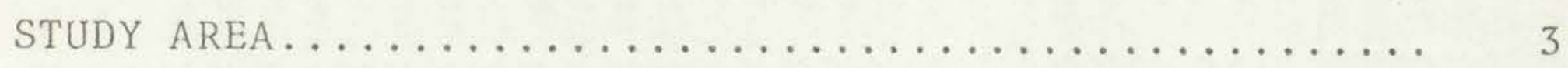

HABITAT SELECTION....................... 12

PERTURBATION STUDIES...................... 17

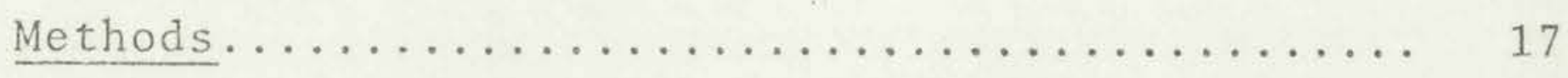

Results........................... 21

DISCUSSION ........................... 31

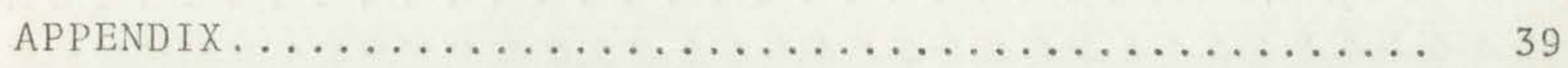

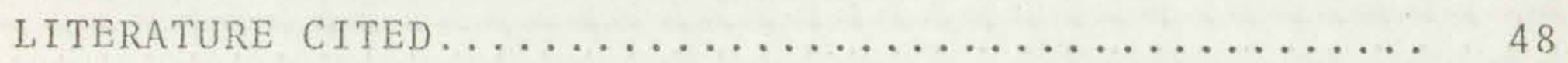





\section{LIST OF FIGURES}

Figure

Page

1 Trap distribution on each unenclosed 16 hectare

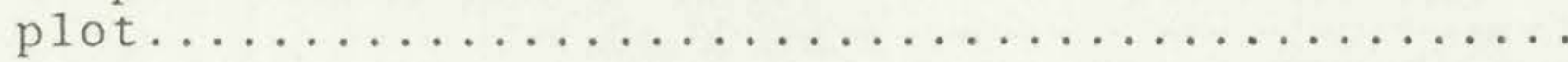

2 a Location of Dipodomys' captures January 25 on

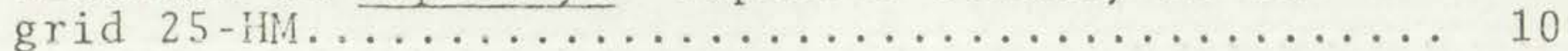

2b Location of Dipodomys' captures August 21 on

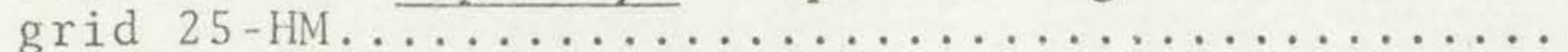

3 D. merriami population changes on controls and merriams perturbed plots............. 23

4 D. ordii population changes on controls and

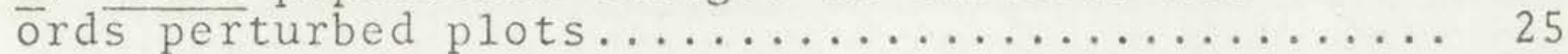

5 D. ordii population changes on controls and merriams perturbed plots................ 26

6 D. merriami population changes on controls

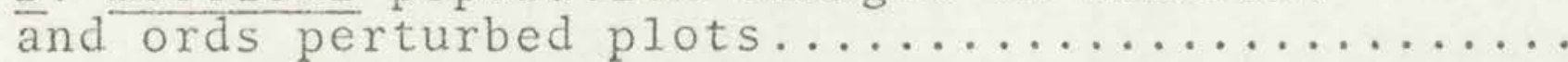

7 Four row curves showing the effect of altering the trap interval on the percent capture/ percent traps $\left(R_{i}\right)$ 



\section{LIST OF TABLES}

Table

Page

1 Heteromyid utilization of grass and creosote bush habitats on ecotonal grids............. 13

2 Predicted competition coefficients determined from overlap in habitat utilization........... 15

3 Grid treatment in perturbation experiments....... 19

4 Population changes during augmentation experiments.......................... 30

5 Analysis of Dipodomys' captures on ecotonal grids: Suitability of trap interval and area

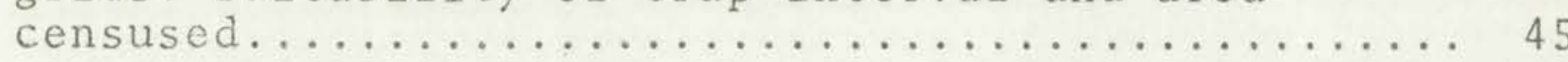





\section{INTRODUCTION}

The coexistence of heteromyids in arid regions of North America has become a subject of considerable interest to some students of natural communities. In areas of Nevada and Arizona it is common to capture, on the same trapping grid, four to six species of heteromyids whose apparent similarities in ecology and ethology invite studies of how they avoid competitive exclusion (Hoffmeister and Goodpaster, 1954; Brown, 1973). All are seed-eating, nocturnal burrowers and one requisite for which these rodents might compete is food. One field study indicates that different heteromyid species may select seeds according to size (Brown and Lieberman, 1973), but another study (Smigel and Rosenzweig, 1974) shows that this is not always the case.

In their theoretical analysis of competitive strategies, MacArthur and Levins (1964) predict that species which spend most of their time searching for small items of food should not pass up many, but should reduce competition by evolving means to exploit slight differences in their habitat. This theory agrees with the conclusions of Rosenzweig (1973) whose habitat tailoring experiments showed that Dipodomys merriami and perognathus pennicillatus prefer different habitats. Similar indications of the importance of habitat selection occur in Brown and Lieberman (1973) and Rosenzweig, Smigel and Kraft (in press). 

Most of these studies attempt to determine how heteromyids partition their environments, but the degree to which any of these species actually compete has never been directly measured. The purpose of this study is to measure the competition between D. ordii and D. merriami by observing their responses to manipulations of their populations on large, unenclosed plots. The ranges of these species overlap extensively in north-central Mexico, southern New Mexico and southern Arizona. They are strikingly similar in size and morphology, and little is known of ecological or ethological differences which may allow them to coexist. What factors influence the local abundance of these species within their common geographical range? To what extent do they compete where they are sympatric? How important is immigration in maintaining local population densities? How do the actual competititve alphas obtained from perturbations experiments in the field compare with estimates of alphas obtained by measuring species overlap in habitat and/or food utilization? These questions are examined in this study. 

STUDY AREA

A preliminary, spot-trapping survey of suitable habitats in central New Mexico was undertaken during March and April 1972. Sherman aluminum live traps (75 X 75 X 250 mm) were used then and throughout the study. A 12 section area $19 \mathrm{~km}$ east and $13 \mathrm{~km}$ south of Socorro, Socorro Co., New Mexico was found to have adequate populations of D. ordii and D. merriami, as well as high densities of Perognathus flavus and substantial numbers of D. spectabilis. Other rodents trapped in the area during the experiments include Peromyscus leucopus, Onychomys leucogaster, Neotoma albigula, Sigmodon hispidus, peromyscus eremicus, Reithrodontonys spp., Perognathus penicillatus, Spermophillus spilosoma, and Geomys bursarius. The entire area is grazed by cattle. Their density averaged from 2 to 20 head per section depending on the time of year and the condition of the grass.

This land is situated along a geological transition zone at the northwestern edge of the Jornada Del Muerto. Here the broad, grassy plain of the valley abruptly meets a band of low, rocky hills and sandy arroyos which parallels the Rio Grande. Soil texture in the hilly region varies from bare, rocky outcrops along the tops of the hills to a loose mixture of sand and rock fragments on the hillsides and, finally, to deep, loose sand in the bottom of the arroyos and in isolated dune areas. On the plains to the east the soil texture is less variable and can be best 

described as a thin layer of loose sand over a firm, sandy substrate. The elevation within the area ranges from 1500 to 1650 meters.

A remarkable change in the plant communities accompanies the soil and topographical transitions. Creosote bush (Larrea divaricatta) is the dominant plant over most of the hilly regions and extends as far as $1 \mathrm{~km}$ eastward onto the sandy plain. Perennial and annual grasses become more common as the soil becomes sandier until, on the eastern plain, creosote bush exists only in isolated patches. Sporobolus cryptandrus, Aristida sp., Muhlenburgia sp., Tridens sp., Bouteloua eurtipendula, Andropogon sp., Mentzilia pumila, and Gutierrizia sarothrae are common in this area. Russian thistle, Salsola kali, is also abundant. Yucca glauca and mesquite, Prosopis juliflora, are widely dispersed over areas with a sandy soil.

The transition zone between the flatland and hillside plant communities is a narrow band along which grasses replace creosote bush as the dominant plant type. The extent to which grass is intermixed with creosote bush within this ecotone is dependent to a great degree on rainfall. The average annual precipitation at the Socorro weather station $24 \mathrm{~km}$ away is $22.3 \mathrm{~cm}$. Two thirds or more of this falls between 1 May and 30 october in spotty, but often torrential thundershowers. Winter precipitation is rare. The mean temperature for July, the hottest month, is $26^{\circ} \mathrm{C}$, 

and midday temperatures often exceed $38^{\circ} \mathrm{C}$ before the onset of the summer rains. Winters are mild although the temperature may occasionally drop below $-12^{\circ} \mathrm{C}$ at night.

More extensive sampling of this area took place from March to September 1972 to determine the detailed distribution of the three dominant heteromyid species. It provided evidence for several important generalizations regarding their distribution. Trapping in a variety of habitats across the entire 12 section area showed that D. merriami (merriams) were rarely trapped in areas 1 acking creosote bush. Three individuals were the only exceptions to this rule and they were trapped only once on grids lacking Larrea. Dipodomys ordii (ords), however, were seldom captured in areas totally lacking grasses as part of the plant community. Perognathus flavus was the most ubiquitous species; it was captured in all habitats included within the study area.

A high abundance of kangaroo rats and a maximal distance between proposed grid sites were the two factors which determined the locations of the 10 trapping grids established within the area. Each unenclosed, hexagonal grid included 16.2 ha. within the outer perimeter of traps. Each grid was actually sampling about 20 ha. The location of 331 trap sites was marked within each grid using surveying equipment. Trap sites were arranged in 10 concentric, equilateral hexagons with a trap interval of 25 meters (Fig. 1). This was found to be the optimal trap interval 

for the density of kangaroo rats encountered on most grids during these experiments. Diminishing the trap interval provided no better census estimates; increasing it created competition for traps between the animals. The methods devised to determine this interval as well as the area trapped by unfenced grids of this type are described in the appendix.

The transition zone, where the two plant communities joined provided suitable habitats for all three species of heteromyids. Five permanent trapping grids (13-LO, 24-C, 24-LM, 25-HM, and 1-C) were spaced at intervals of 1 kilometer or more along the ecotone. The eastern margin of the Larrea divided grids 1-C, 25-HM, 24-C and 24-LM approximately in half. The eastern $\frac{1}{2}$ of each of these plots was grassland. A broad extension of grassland extended into 13 -LM, although creosote bush dominated much of the grid. Plots $12-\mathrm{HO}$ and 2-liM were sinilar in that both had extensive areas of sand dunes topped with mesquite, Yucca, and clumps of grass as well as rockier areas dominated by creosote bush.

Grids 30-HO, 30-LM, and 36-LO were on the eastern half of the study area where grasses and annuals were the predominant plant types. Most of the acreage included within these three grids was typical of the area. However, encompassed within grid $30-L M$, was a ten acre island of Larrea which was isolated from the ecotone by a kilometer 



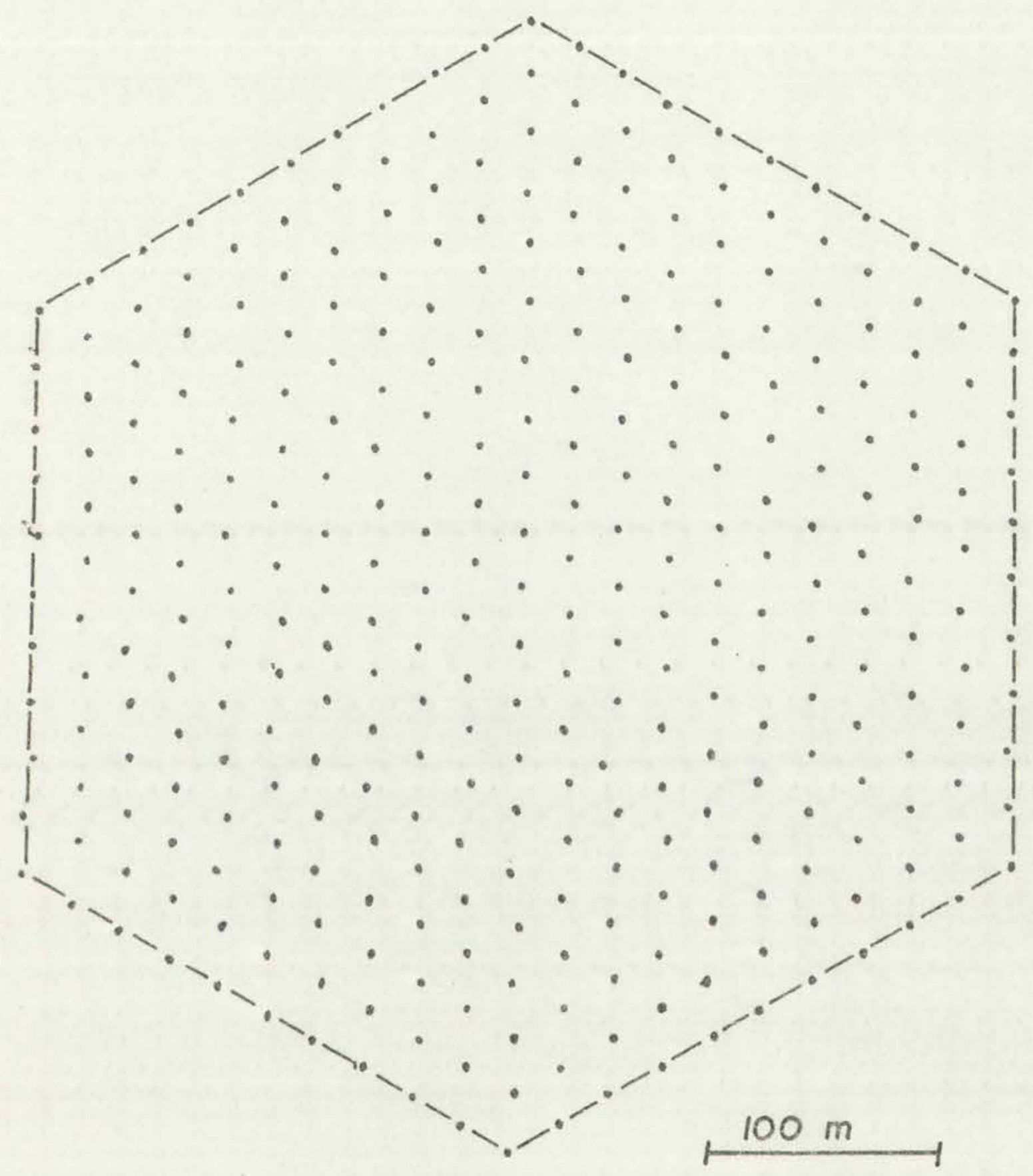

FIGURE 1. Trap distribution on each unenclosed 16 hectare plot. 

of grassland. Prairie grass was extremely sparse within this island and dense thickets of dry tumbleweed accumulated around the bases of many of the creosote bushes. P1ot 36-LO contained an isolated, 10 acre patch of mesquite, sparsely distributed creosote bush, and dense thickets of dead tumbleweed. The soil texture within these two islands did not appear to differ from that in the surrounding grassland.

During the period of these investigations the distribution of $\underline{D}$. ordii changed, probably in response to the unusually high precipitation during the summer and winter of 1971. When spot-trapping began in March 1972, the grass was sparse and grazed to within a few inches of the ground over much of the eastern plain. D. ordii were not found where the effects of the drought were greatest. Good concentrations survived, however, in the limited grassy areas .

Rainfall was moderately high in the summer of 1972 , and the grass began to return that fall. Several significant snowfalls that winter and better than average spring and summer showers brought about a tremendous growth of grasses and annuals in 1973. Grasses, Russian thistle, and other annuals became common in sandier areas of the ecotone previously occupied by creosote bush as we11 as on the adjoining plain. This pattern of plant distribution persisted during the remainder of the experiments. 
The change in distribution of $\underline{D}$. ordii on the ecotonal grids coincided with the spread of grass across these plots in the spring and early summer of 1973. The appearance of $\underline{D}$. ordii in this area brought them into greater contact with the $\underline{D}$. merriami which occupied the ecotone throughout the period. This change in ords distribution and abundance is illustrated in Figures $2 \mathrm{a}$ and $2 \mathrm{~b}$. These are maps of grid 25 -HM showing the location of a 11 ords and merriams captures on 25 January and 21 August, 1973. The curved line indicates the eastern border of Larrea on this grid. These two dates are near the temporal extremes of the experiments, but capture maps from the intervening months show that the westward advance of $\underline{B}$. ordii accompanied the emergence of new grass on all grids along the ecotone. 



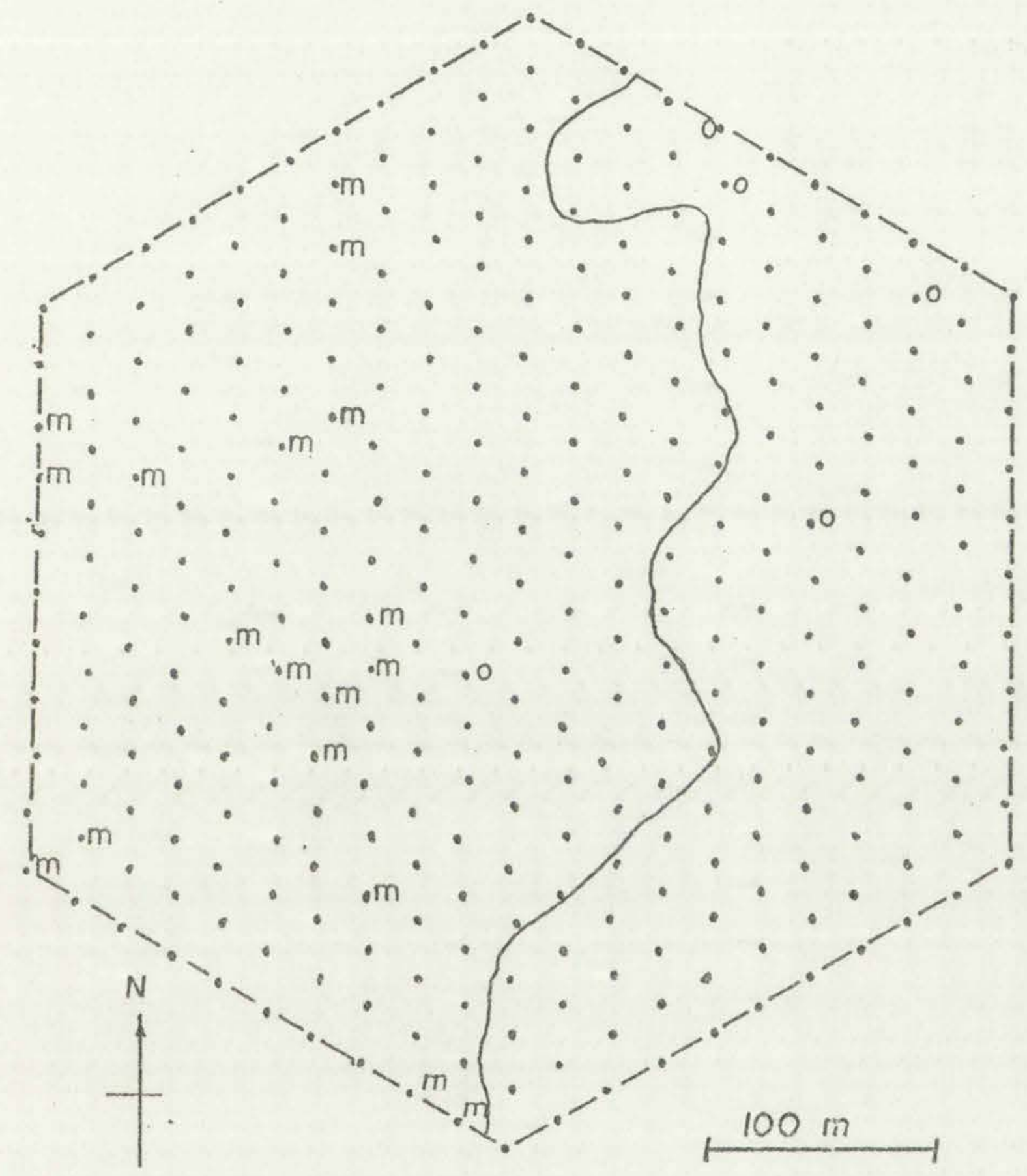

FIGURE 2a. Location of Dipodomys' captures January 25 on grid 25 -HM. 



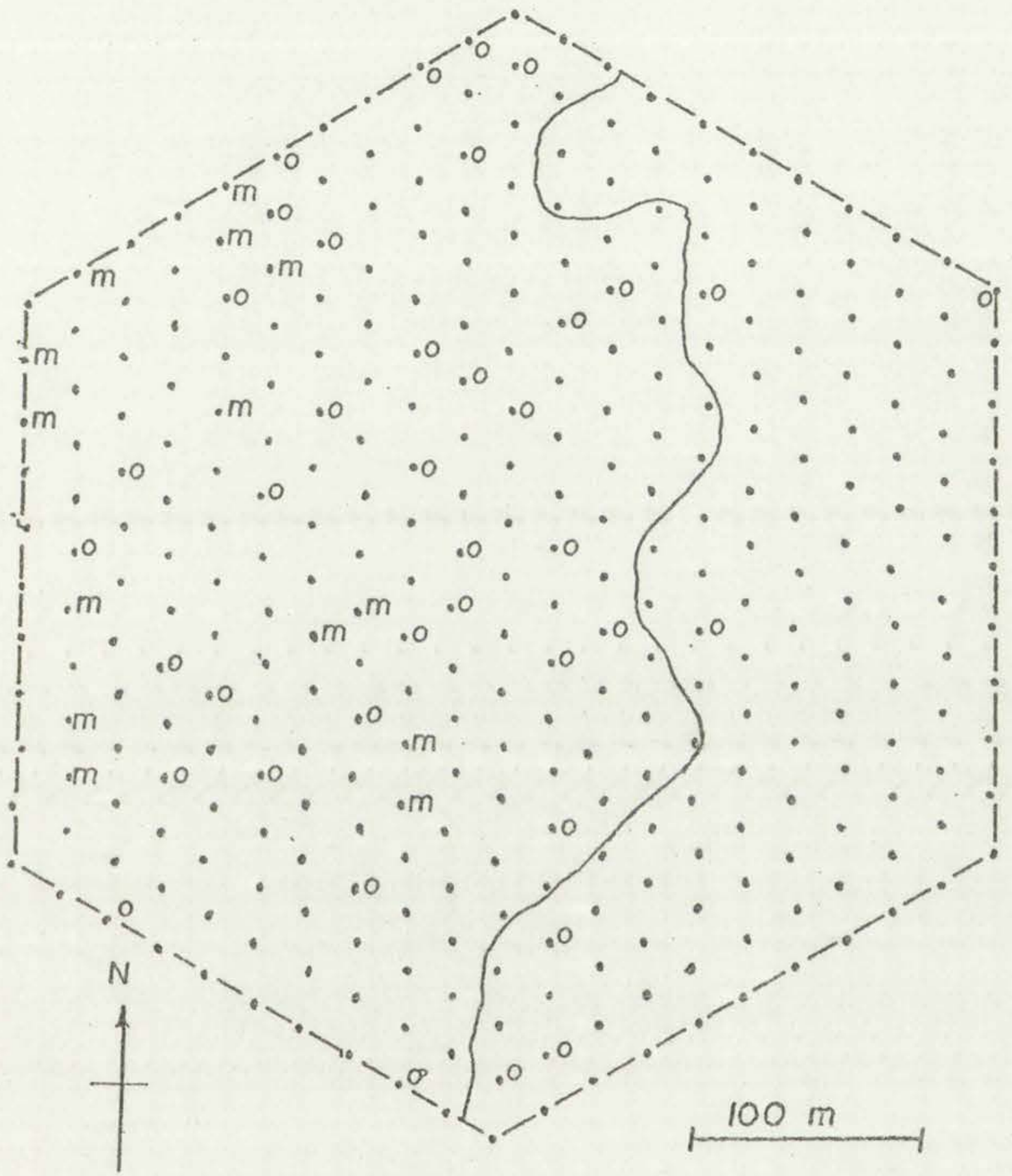

FIGURE 2b. Location of Dipodomys' captures August 21 on grid $25-\mathrm{HM}$. 



\section{HABITAT SELECTION}

The apparent habitat preference shown by the two kangaroo rats in this area suggested that this may be a means by which they reduce competition, and prompted an attempt to quantify the extent to which grass and creosote bush control their distribution. Thus, during August 1973 every trap site on each of the five ecotonal grids was ranked on the basis of the type of plant coverage present within a 10 meter radius of the trap.

A visual estimate of the area covered by grasses relative to that covered by creosote bush was the basis for assigning each trap site a score from 1 to 4 . A site covered entirely by grass was given a score of 1 . A rating of 4 meant that creosote bush provided the only cover, and that little or no grass was present. Frequently an area would have a high density of Larrea with dense clumps of grass interspersed among the bushes. Such trap sites received a score of 3. Areas dominated by grasses and dotted with a sparse distribution of creosote bush were given a score of 2 .

The records from the two control grids made between mid May and early september reveal how the two species of Dipodomys were distributed. Table 1 gives a summary of this data including the mean habitat value and standard deviation for the three species of heteromyids on all five ecotonal plots. The table also includes the same 

TABLE 1. Heteromyid utilization of grass and creosote bush habitats on ecotonal grids.

\begin{tabular}{|c|c|c|c|c|c|c|c|c|}
\hline $\begin{array}{c}\text { Grid } \\
\text { (Mean - S.D.) }\end{array}$ & Species & $\begin{array}{l}\mathrm{H} \\
1\end{array}$ & $\begin{array}{r}\text { labit: } \\
2\end{array}$ & & $\begin{array}{l}C 1 \text { as }{ }^{a} \\
3 \quad 4 \\
\end{array}$ & Me an & S.D. & $\underline{x}^{2}$ \\
\hline$(2.05-.98)$ & $\frac{\mathrm{D}}{\overline{\mathrm{D}}} \cdot \frac{\text { merriami }}{\mathrm{p}} \cdot \frac{\text { ordi } \mathrm{flavus}}{\underline{\text { fla }}}$ & $\begin{array}{r}5 \\
17 \\
89\end{array}$ & $\begin{array}{r}8 \\
1 \\
66\end{array}$ & $\begin{array}{l}91 \\
3 \\
98\end{array}$ & $\begin{array}{r}8 \\
6 \\
14\end{array}$ & $\begin{array}{l}2.91 \\
2.49 \\
2.14\end{array}$ & $\begin{array}{r}.56 \\
1.04 \\
.95\end{array}$ & $\begin{array}{l}24.2 \\
19.5\end{array}$ \\
\hline $\begin{array}{l}24-C \\
(2.32-.99)\end{array}$ & $\frac{D}{\bar{D}} \cdot \frac{\text { merriami }}{\frac{\text { ordii }}{\text { flavus }}}$ & $\begin{array}{r}0 \\
22 \\
127\end{array}$ & $\begin{array}{r}4 \\
48 \\
120\end{array}$ & $\begin{array}{r}102 \\
227 \\
96\end{array}$ & $\begin{array}{l}90 \\
64 \\
10\end{array}$ & $\begin{array}{l}3.44 \\
2.92 \\
1.97\end{array}$ & $\begin{array}{l}.54 \\
.74 \\
.86\end{array}$ & $\begin{array}{r}68 \\
197\end{array}$ \\
\hline
\end{tabular}

Experimentals $\mathrm{b}$

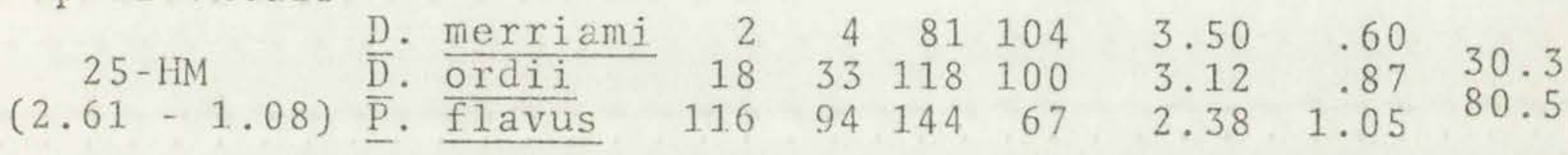

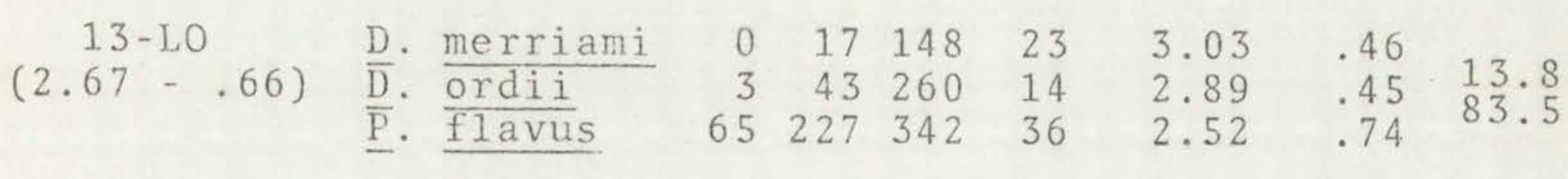

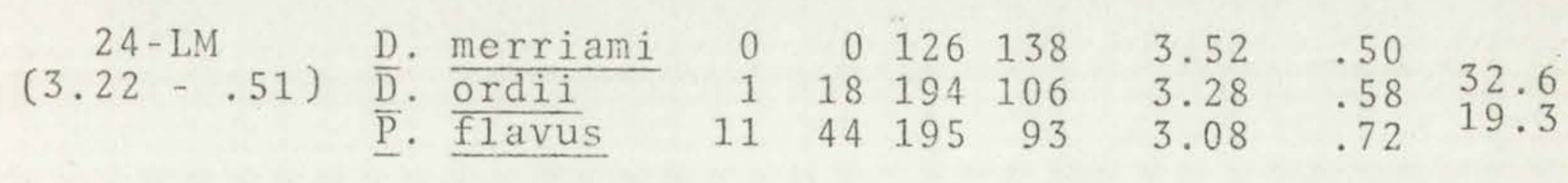

a. 1 = pure or nearly pure grasses and herbs; $4=$ pure or nearly pure creosote bush. Numbers in the body of the table are the number of captures of a species on a plot in a particular habitat class.

b. Experimental manipulations will be described latér. They are not important here as there was no difference between control and experimental results.

c. See text for description. 

statistics gathered for all the trap sites on each grid; these statistics provide a means of comparing how the grids differ with respect to the creosote bush - grass variable. A chi-square analysis was used to test the hypothesis that two species (e.g. D. ordii and D. merriami) utilize each of the four habitats in the same proportions. This analysis was applied separately to the data from each grid and showed that $\underline{D}$. ordii tends to be captured in a significantly $\left(\underline{\mathrm{P}}_{3}<.01\right)$ grassier habitat than $\underline{\mathrm{D}}$. merriami and that $\underline{P}$. flavus was taken in a habitat significantly $\left(\underline{P}_{3}<.01\right)$ grassier than either kangaroo rat (Table 1 ).

Despite significant differences, each species was caught in a broad range of habitats (Table 1). An estimate of their habitat overlap was computed using the equation of MacArthur (1972).

$$
\alpha=e^{-d^{2} / 2\left(S_{1}^{2}+s_{1}^{2}\right)}
$$

Where $\alpha$ is a competition coefficient, $\underline{d}$ is the difference in the mean values of the habitat variable measured for the two species, and $\mathrm{S}_{1}$ and $\mathrm{S}_{2}$ are their respective standard deviations. The habitat overlaps between $\underline{\mathrm{D}}$. ordii and D. merriami and between $\underline{\mathrm{D}}$. ordii and $\underline{\mathrm{P}}$. flavus yield coefficients ranging from .70 to .97 on the two control grids (Table 2). Overlap values from the experimentals are similar but may be biased by the experiments and are reported only for information. Thus, despite evidence the species prefer habitats which are measurably different, 

TABLE 2. Predicted competition coefficients determined from overlap in habitat utilization.

Species

1-C $24-\mathrm{C} \quad 25-\mathrm{HM} \quad 13-\mathrm{LO} \quad 24-\mathrm{LM}$

D. merriami - D. ordii .94

D. ordii - P. flavus .97

D. merriami - $\underline{\text { P. flavus }} .78$
Grids

.94

.98

.95

.91

.98

84

.88 

each forages over a broad spectrum of the available habitat and, according to the overlap formula, are likely to compete intensively. This conjecture seems especially probable since both Dunham (1968) and Erown and Lieberman (1973) noted significant overlap in the diets of ords and merriams. 


\section{PERTURBATION STUDIES}

The only necessary and sufficient means of demonstrating the existence of competition between two species is to observe the numerical responses of the presumed competitors to perturbations of one or both species. For instance, the population of a species would increase and/or its distribution expand if the density of its competitor is depressed. This follows directly from the general definition of interspecific competition (Rosenzweig, 1970). This was the approach used to determine the relationship between $D$. ordii and $D$. merriami on the 10 plots. These two species were selected for study because they have very similar morphology and size. It was, therefore, supposed that they were the strongest competitors. Moreover, unlike the pocket mouse, they are easily marked and remain active in the winter. The initial intention was to measure the degree of their interaction through fractional perturbations of their populations on 8 grids with 2 grids reserved as controls. This approach was abandoned, however, due to inadequate manpower, and the problem was more closely studied on the 5 ecotonal grids.

\section{Methods}

Censuses and perturbations of the plots began in January 1973. The treatment each plot received was determined by the relative size of its two Dipodomys populations. Normally the population of the more common species was 

depressed. However, D. ordii was by far the more common species on most grids at this time. Thus, to conform with the experimental design, it was necessary to remove $\underline{D}$. merriami from plot 2 -HM although the D. ordii population on that grid was larger.

The two grids having high D. ordii population (12-HO, 30-HO), and two grids having high D. merriami populations (25-HM, 2-HM) received the heaviest perturbations. On each of these grids the population of the predominant species was decreased by two thirds. On two other grids having substantial D. ordii populations (13-LO, 36-LO) one third of that species was removed. One third of the D. merriami population was removed from grids 24-LM and 30-LM. No individuals of either species was ever removed from the control grids (24-C, 1-C). A summary of these treatments can be seen in Table 3 .

Grids were trapped for two consecutive nights. A single live trap was placed at each trap site and baited with a commercial mixture of "wild bird food" consisting mostly of millet, milo, and sunflower seeds. During the winter months traps were checked in the early morning between $1: 00$ and $4: 00 \mathrm{AM}$ and the animals released to prevent their death by freezing. During the warmer months this procedure began at first 1 ight.

Species and trap location of every animal captured was noted. A11 D. ordii and D. merriami were marked by clipping 

TABLE 3. Grid treatments in perturbation experiments $0=$ D. ordii, $m=$ D. merriami.

\begin{tabular}{|c|c|c|c|}
\hline Grid & & $\begin{array}{l}\text { Percent } \\
\text { Removed }\end{array}$ & $\begin{array}{l}\text { Species } \\
\text { Removed }\end{array}$ \\
\hline $24-L M$ & $\mathrm{~b}$ & 33 & $m, o^{b}$ \\
\hline $30-\mathrm{LM}$ & & 33 & $\mathrm{~m}$ \\
\hline $2-H M$ & & 67 & $\mathrm{~m}$ \\
\hline $25-\mathrm{HM}$ & c & 67 & $\mathrm{~m}$ \\
\hline $13-10$ & $a, c$ & 33 & 0 \\
\hline $36-\mathrm{LO}$ & & 33 & 0 \\
\hline $12-\mathrm{HO}$ & & 67 & 0 \\
\hline $30-\mathrm{HO}$ & & 67 & 0 \\
\hline $1-\mathrm{C}$ & & 0 & none \\
\hline $24-C$ & c & 0 & none \\
\hline
\end{tabular}

a. Received maximal D. ordii perturbations $8 / 1-9 / 6$.

b. D. merriami perturbations discontinued $7 / 13$, then received maximal D. ordii perturbations on $7 / 31$ and $8 / 14$.

c. Grids used in augmentation experiment. 

a numbered, fingerling fish tag to their ear when first captured. This number was recorded with each subsequent capture. In addition, the species, location, sex, and apparent age and reproductive condition of each kangaroo rat was noted. These data were taken in the field, and all animals, not to be removed, were released at the point of capture. Al1 traps were closed in the morning and rebaited in the afternoon.

The size of the Dipodomys' populations were estimated using the Lincoln Index formula, $x=m t / r$, where $x$ is the estimated size of the population, $\underline{m}$ is the number of animals marked and released the first morning, $\underline{t}$ is the total number captured the second morning, and $\underline{r}$ is the number of animals released the first morning and recaptured the second. Also, minimum estimates of population size were arrived at by totalling the number of different individuals captured over the two night interval. With few exceptions the Lincoln estimates were in good agreement with the minimum estimates.

Perturbations were made the second morning of each visit to a grid. From January to June one grid a week was censused and perturbed. These manipulations were designed to maintain the perturbed species on each grid at the density to which it was reduced following the first perturbation. If $30 \mathrm{D}$. ordii were trapped on the first visit to a grid and one third were removed, then the density 

of that species would be reduced to 20 on the first and on al1 subsequent perturbations of that population. Thus, during this period the density to which the perturbed species was reduced on each grid following the first census was the density approached in the subsequent manipulations. In August and September, maximal perturbations were conducted on several grids. These involved the removal of all individuals of the manipulated species captured during the second night of trapping.

When only one grid per week was sampled, an interval of 10 weeks elapsed between consecutive censuses of each grid. Such infrequent visits were found inadequate to maintain the desired levels of perturbation, so all efforts from early June to late September were concentrated on the five grids along the ecotone. During this period grids 24-C and 1-C continued as controls, but the other three grids received frequent manipulations. Between 1 August and 6 September, grid 13-LO received maximal ords perturbations at 10 day intervals. Grid 24-LM, from which merriams had previously been removed, received a maximal ords perturbation on July 31 and again on August 14 in an attempt to release the ords - occupied habitat to immigrant D. merriami.

\section{Results}

Since the mininum census estimates agree well with Lincoln estimates, only the former will be presented and discussed. 

The changes which populations of $\underline{D}$. merriami underwent on the four grids where they were the manipulated species are shown in Figure 3. Census data for this species on the two control grids (1-C, 24-C) are included for comparison. Grids 2-HM and 25-HM had two thirds of their merriams populations removed following their first censuses, and 24-LM and 30-LM had one third removed at this time. At each subsequent census until late July each population was returned to its initial perturbed density. The similar perturbations of four D. ordii populations are in Figure 4 , which also includes census data for ords populations on the control grids.

Perhaps the most impressive thing which these two figures show is the resiliency of these species. The perturbed populations of $\underline{D}$. merriami seem capable of renewing most lost individuals through immigration in three months or less (Fig. 3). This is demonstrated by the recovery of this species on 24-LM and 25-HM between mid January and early May. These two grids were located on the transition zone and were easily accessible to floating populations of both ords and merriams. However, grids 30 -LM and, to a lesser extent, 2 -HM were more isolated from sources of merriam immigration and show slower rates of recovery. ‥ merriami populations may have suffered a period of natural decline in the spring and early summer as indicated by data from the control populations (Fig. 3). 



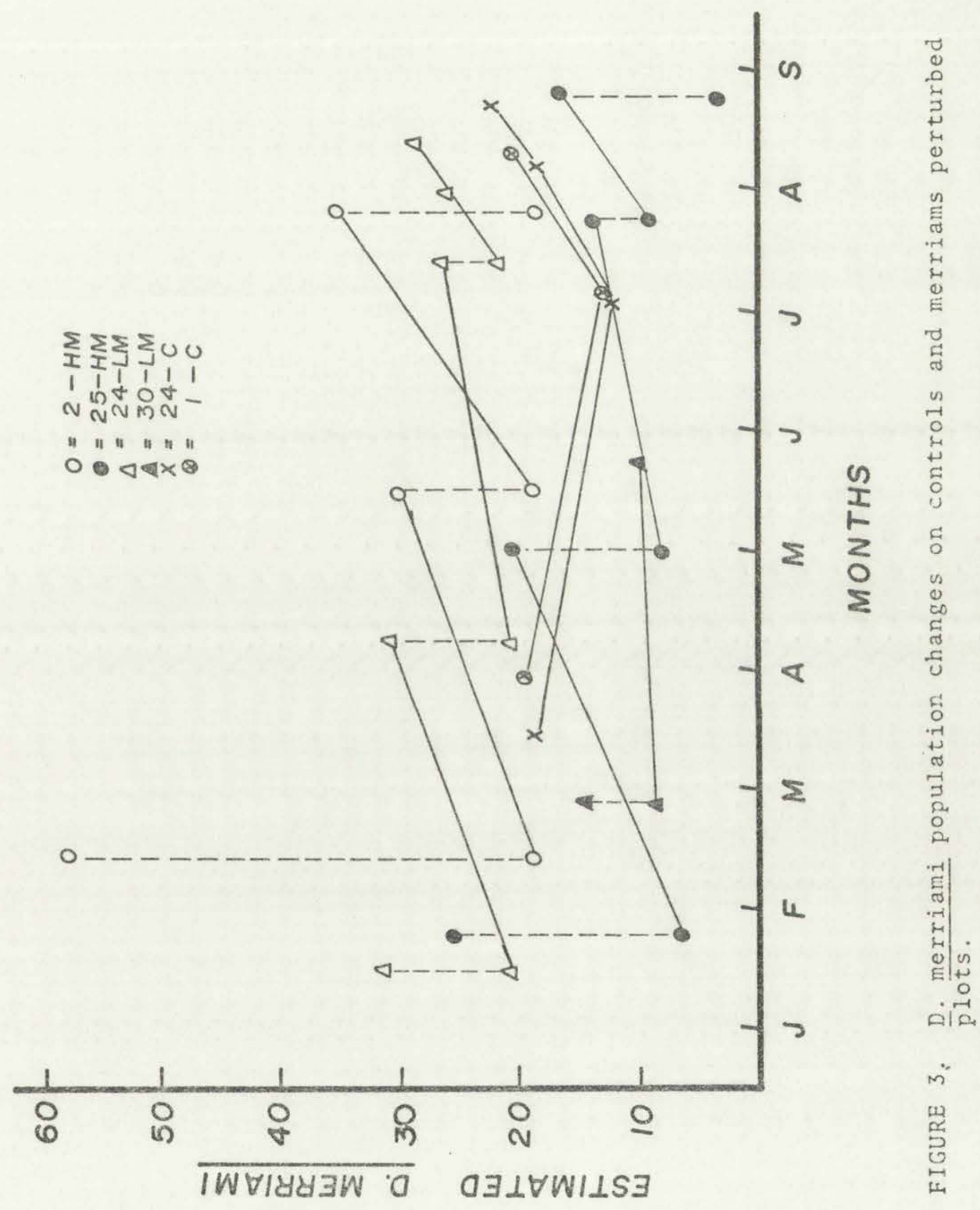



In June or July the populations on the controls began a period of increase which continued through the last census date.

The ords populations on the control grids followed a pattern of general increase throughout the early months of the experiments (Fig. 4). Both, however, showed little change in June or July followed by continued increases on 24-C throughout August and early September. Perturbed populations of D. ordii on 13-LO, 12-HO, and 30-HO show high recovery rates. The best example of this is the ords population on grid 13 -LO which responded to perturbations administered at 10 day intervals in July and August by replacing an average of three animals per day. That amounts to about five percent of carrying capacity per day. Moreover, since this is an integral of a rate over 10 days, it is probably an underestimate of the initial, peak rate.

The effects of these nanipulations on the second species sharing each grid are negligible (Figs. 5 and 6). On the four grids which received merriams perturbations, the ords populations do not show the increases one would expect if the two species were competing (Fig. 5). The changes demonstrated by these populations follow very closely the changes seen in this species on the controls. D. merriami populations on the four ords perturbed grids followed the same slight decline in density seen on the control grids between May and July (Fig. 6). A major ords perturbation 



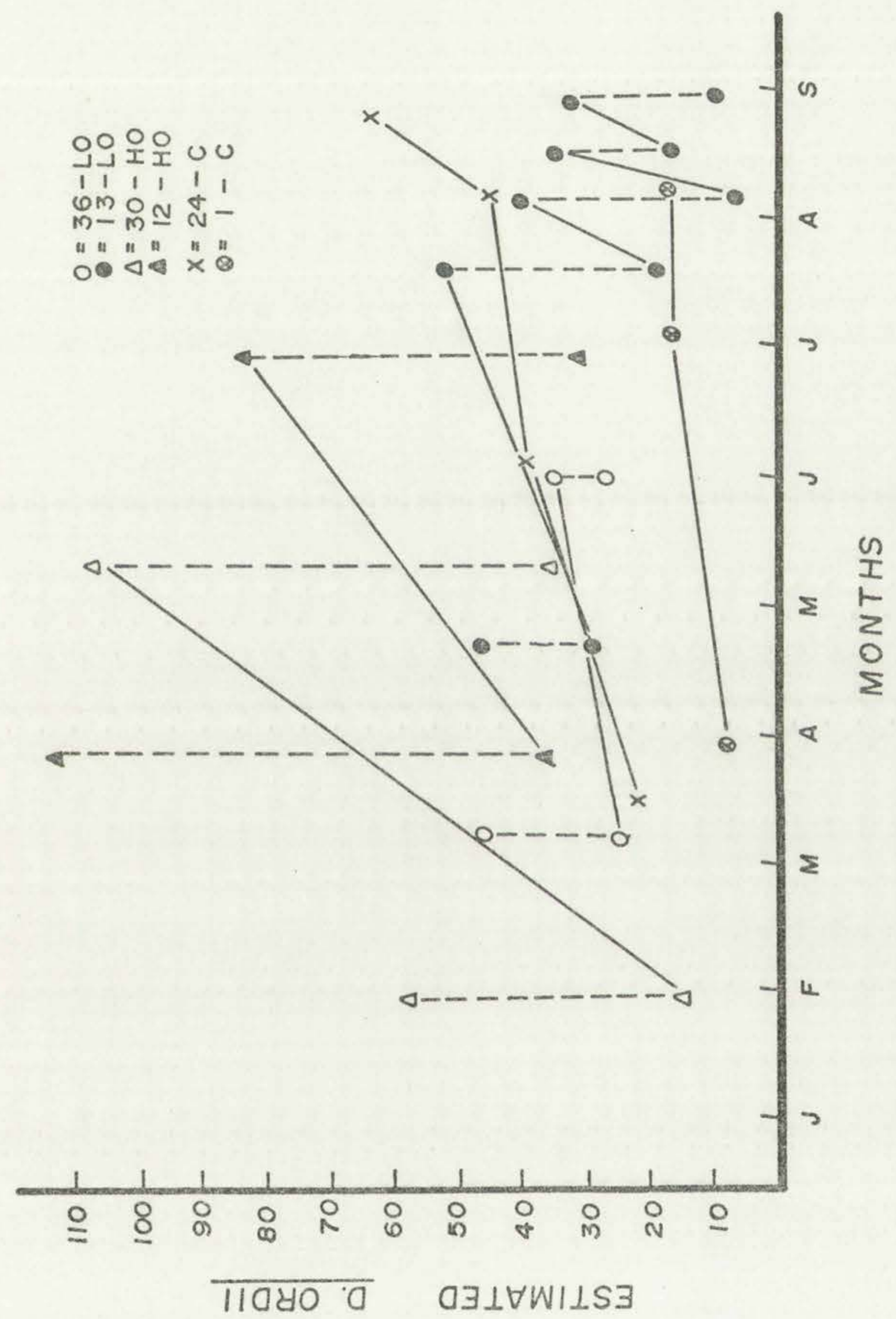

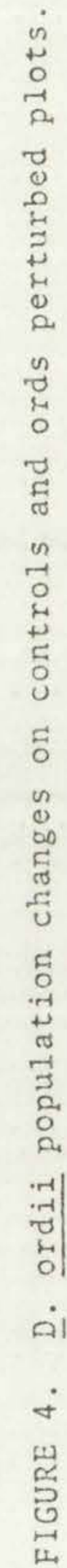





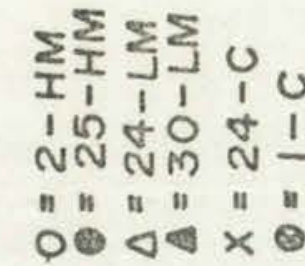

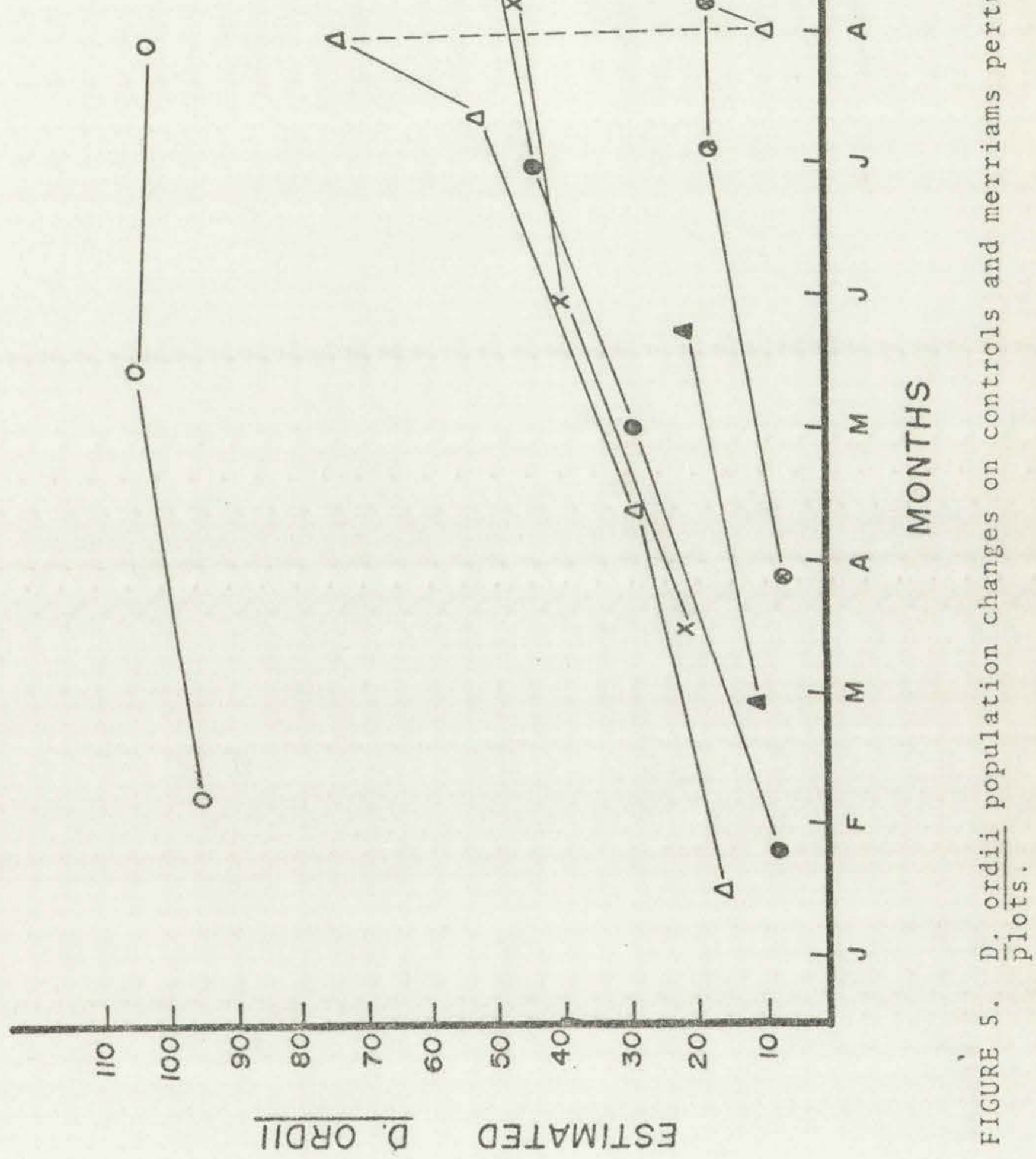




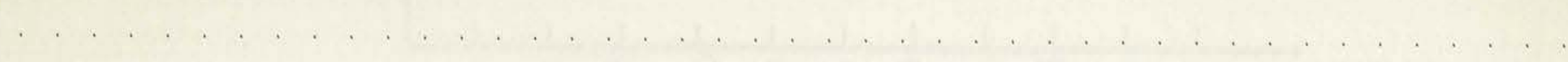




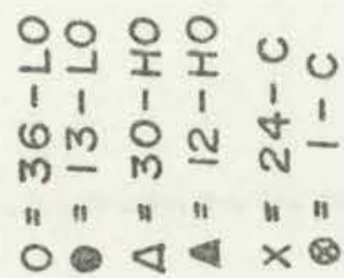

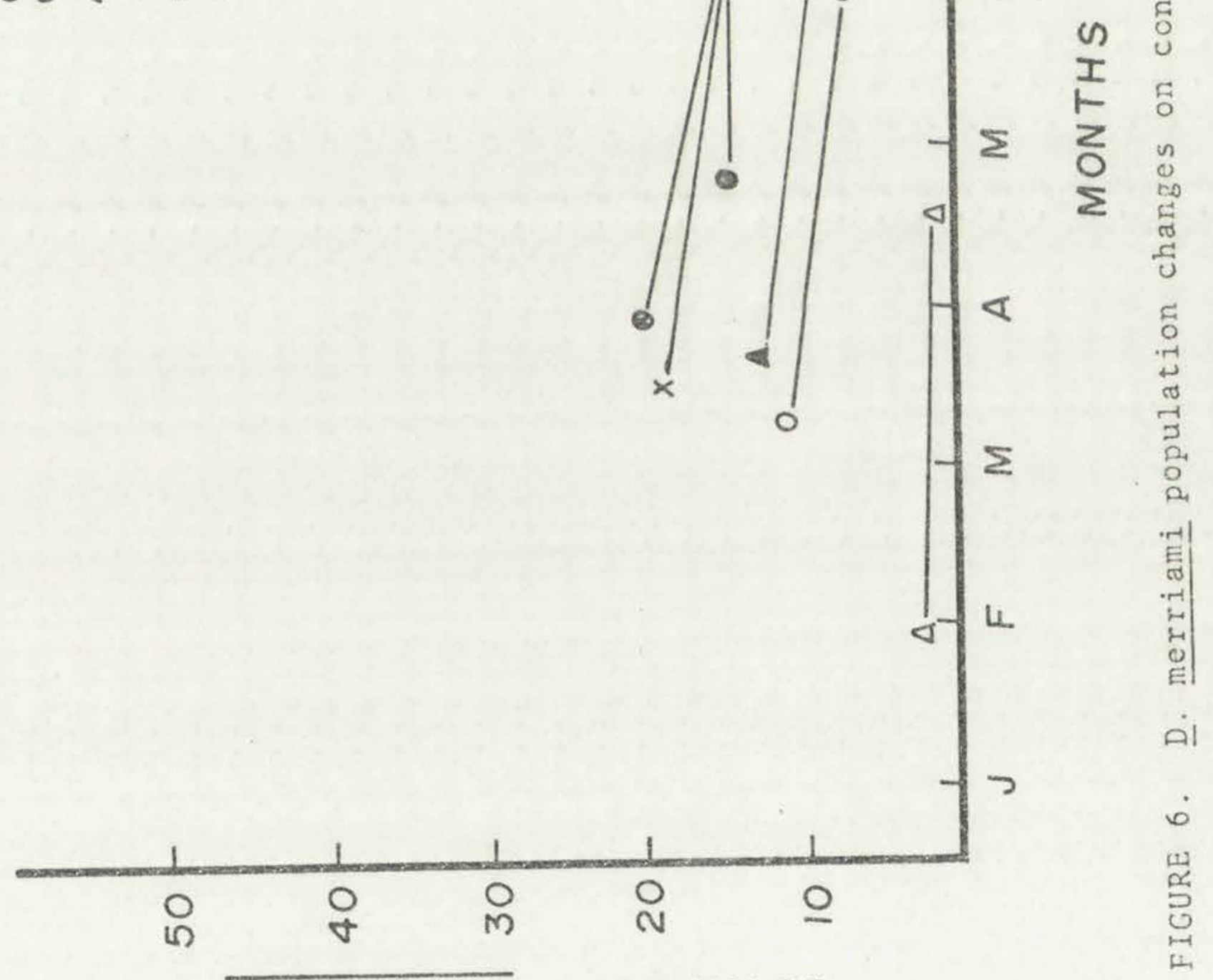

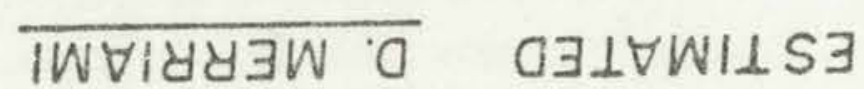




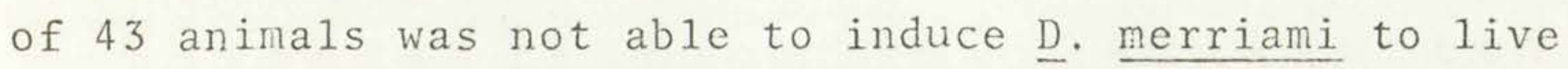
in the grassy habitat included within grid 30-HO.

The grid which received the most intensive trapping was 13-LO. An effort was made from mid July to the end of August to remove as many $\underline{D}$. ordii as possible from this grid, and the success of this trapping can be seen in Figure 4. A total of 110 animals was removed within this six week period. The D. ordii population decreased from 53 to as few as 6 animals. These efforts may have had the effect of enhancing the rate of $\underline{D}$. merriami increase on the grid during this period to a level slightly above that of the merriams on the controls (Fig. 6). However, the difference in these rates of increase do not appear to be significant. It is apparent from these experiments that when an animal is removed from any population it is quickly replaced by another member of the same species and not by its congener. To further confirm this, a brief series of augmentation experiments were conducted from August 20 to September 5 which tested the relative effects of $\underline{D}$. ordii and D. merriani densities on the ability of immigrant D. merriami to persist for 10 days in new areas. Following a maximal perturbation of ords on 13-LO and of merriams on 25-HM, 15 freshly captured D. merriami from other locations were released on each of these grids (as well as 15 on the control grid 24-C). This addition of marked animals occurred on the two nights immediately following the perturbations 

(or the census on the control); six animals were released in the center of each grid the first night and 9 animals the second night. After 10 days each grid was recensused. The D. ordii population on 13 -LO was reduced from 33 to 10 known inhabitants, and the D. merriami population on 25-HM reduced from 17 to 3 individuals. A census of the control grid showed that it held 23 merriams and 64 ords before the new merriams were released. Of the 15 "immigrant" merriams released on each of these grids, 5 were recovered on 13-LO, 5 on 24-C and 9 on 25-HM (Table 4). Natural migration also occurrea on these grids during the 10 day interval between censuses, so the net changes in the populations are also of interest. The merriams control population $(24-C)$ increased by 7 (30\%) including the 5 seeded immigrants. This species increased by 14 (43\%) on 13-LO and by $12(400 \%)$ on 25-HM over their perturbed densities. Moreover, although the populations of D. ordii on 25-HM and the control grid changed very little ( $6 \%$ and $-2 \%)$ during this time, the ords increased $140 \%$ on 13 -LO through natural immigration alone. Thus, immigrant D. merriami, whether augmented or natural, did best on 25-HM where it had been the species removed, and D. ordii increased the most on 13-LO where they were the perturbed species. Of course, these numbers are too small for one to conclude anything from them alone, but it is of interest that they conform exactly to the pattern obtained from the other work. 



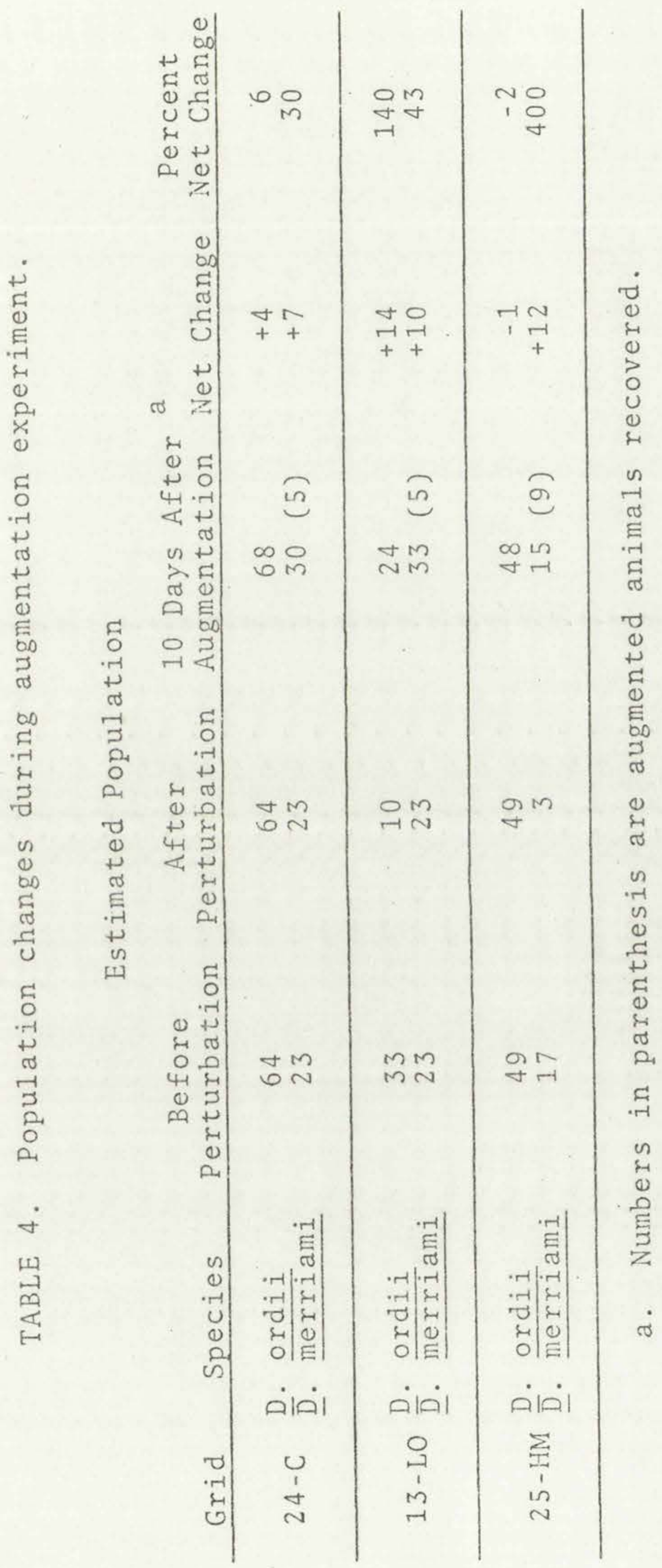





\section{DISCUSSION}

The spatial distribution of the two species of Dipodomys on the site of this study is a classic example of contiguous allopatry. D. ordii is largely restricted to a grass-dominated habitat and $\underline{D}$. merriami to a habitat where creosote bush dominates; both are trapped in a narrow zone of mixed habitat. Miller (1967) states that such a distribution indicates a strong element of competition but warns that it could also be produced by a sharp environmental discontinuity. Were the latter true, the fundamental niche of these species might be set by the same physical and environmental factors which are responsible for the marked transition in plants which occurs along the ecotone separating their prime habitats. The increase of $\underline{D}$. ordii on the ecotonal grids which accompanied the sudden proliferation of grass there, could indicate their physiological need for a more productive environment, a behavioral preference for a grassy habitat or both. There were no other noticeable changes in the environment accompanying the increase in grass; in particular, soil texture remained the same diminishing the possibility that this feature alone accounts for the difference in the distribution of these two species. Although abundant grass is apparently needed to support D. ordii, both species were often captured at the same trap stations implying a significant degree of overlap in their physiological tolerances and behavioral 

preferences. Perhaps, their ranges do have physiological limitations, but these limitations are not sufficient to prevent sympatry and possible competition along the ecotone. Conversely, it would be improper to explain their distribution on the basis of competitive interaction unless it can be shown that the realized niche of one or both species is less than their fundamental niche. The few studies in which free or enclosed populations of animals have been manipulated are cited by Grant (1972) and Miller (1967), and such studies, when done with proper controls, provide the strongest evidence for the presence or absence of competition between the species involved.

The perturbations of the present study suggest that neither species is restricting the density or distribution of the other. Since it was not possible or desirable to restrict immigration into the unenclosed grids, it was difficult to maintain high levels of perturbation. Perhaps the populations of the unperturbed species would have increased had the perturbations been maintained for longer periods. It may be true, in fact, that the merriam population on 13-LO showed a slight increase in response to frequent manipulations of the ords population there, but the consistency with which the perturbed species always bounced back to restore their own depleted populations on every grid suggests that $\underline{D}$ ordii and $\underline{D}$. merriami are orders of magnitude more sensitive to their own 

density than that of their congener. This conclusion is also supported by the results of the augmentation experiment in which the $\underline{D}$. merriami were more successful in remaining on the grid from which merriams had been removed than on the grid from which ords were removed.

The two species of Dipodomys appear to avoid direct competition by means of subtle differences in habitat preference. Although the data from the ecotonal grids indicate that significant differences exist in the habitats preferred by the three common species of heteromyids, the interaction coefficients estimated from this data, range from .85 to .98 and predict a high intensity of competition between the kangaroo rats. However, the perturbation studies offer no evidence of competition between these species. Perhaps this apparent contradiction can be explained by the rather naive way in which habitats were classified. Although the grass - creosote bush variable is adequate to predict which species will be found in the two extreme cases; it might lack the resolution needed to detect the features by which the two species distinguish their optimal habitat where competition is most likely to occur, i.e. where grass and creosote bush are intermingled.

It is possible to permit the rodents themselves to classify their habitats if each trap site is viewed as a potentially different habitat, and its record examined to see the frequency with which each species was captured 

there. If the enticement of a baited trap doesn't greatly alter the animal's foraging habits, trap sites at which both species are captured are habitats in which these species might interact. With this method any subjective evaluation by the investigator is eliminated.

Levins (1968) assumed that competition depends on individuals of two species meeting in or searching the same habitat for food, and proposed a means of measuring a competitive alpha whose magnitude is determined by the probability of interspecific encounters relative to intraspecific encounters. This method was applied to the capture records for the control grids. The record from each trap location was examined and the species of each kangaroo rat captured there was noted. If only one individual was captured at a given location no encounters could be assumed to have occurred there, and its record was not included in the analysis. The encounter coefficients were calculated as follows:

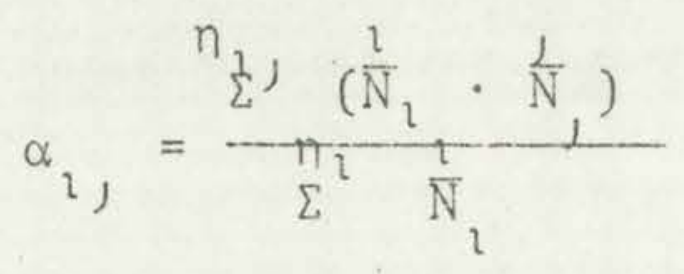

where $n_{1}$ is the number of trap sites where encounter occurred involving two or more individuals of species $?, n_{2}$, is the number of trap sites where interspecific encounters occurred, $\underline{I}$ is the number of individuals of species icaptured at a given trap site, and $N$ is the total number of individuals 

captured of that species at $\eta_{l}$ traps.

The encounter coefficients for $24-\mathrm{C}$ are $\alpha_{\text {mo }}=.26$ and $\alpha_{\text {om }}=.44$. The first measures the impact of ords on merriams and the second that of merriams on ords. Similar coeffecients for grid $1-\mathrm{C}$ are $\alpha_{\mathrm{mo}}=.45$ and $\alpha_{\mathrm{om}}=.29$. The discrepancies in the exact estimates of alpha could be due to various factors, but it is the magnitude of these alphas, not their exact value that is of interest. Compared to what was predicted by the grass - creosote bush variable, interspecific encounters are relatively rare, providing additional evidence that a rather subtle form of habitat selection minimizes or eliminates competition between these two species. Yet even these estimated values of alpha are substantial compared to true alpha which the perturbation work showed to be close to zero.

These experiments followed a period of unusually heavy precipitation which resulted in conditions very favorable to high seed production. Both species responded by population increases, and D. ordii locally extended its range to utilize the new resources. This may have been a period of high seed abundance and low competitive pressure. Would the perturbations have produced similar results under less favorable conditions or at another time of year? Perhaps the differences in habitat preference I observed would disappear, and interspecific competition increase. An answer without new experiments done under clearly 

different conditions would be highly speculative. Certainly, the results of these perturbations would be more convincing if the experiments had been continued for a full year. It is of interest, however, that both Dipodomys have maintained the same distribution relative to the ecotone through April 1974. If they are habitat selectors and their foraging behavior is innate, then short term elimination of either species should not alter this innate preference, and perturbations at any season should yield similar results.

Brown (1973) and Brown and Lieberman (1973) measured the differences in the food selection and foraging locations of seed-eating rodents on 18 sand dunes in eastern California, Nevada, and western Utah. Of the seven dunes within the geographical and altitudinal range of $\underline{D}$. ordii and $\underline{D}$. merriami, these species were captured together on only two. Both species avoid plants and shrubs and forage in the open. They were found to overlap in seed utilization to a moderate degree; D. ordii collected larger sized seeds than D. merriami. These conclusions, however, were based on the combined data including that taken from areas where ords and merriams are not sympatric. Differences may, therefore, reflect only local differences in seed availability rather than differences in seed preference. Collections made by Dunham (1968) and Lemen (pers. comm.) indicate that ords and merriams take the same seeds where they are locally sympatric in New Nexico. Here, resource allocation 
probably plays no part in protecting either from local extinction .

The consistent regularity in the replacement of removed animals by immigrants of their own species in this study suggests that different factors were limiting the abundance of each species. From the nature of their responses, it is possible to infer a few characteristics of these limiting factors. The speed with which animals from outside the grid reacted to the perturbations indicate that they were responding to easily perceived clues such as empty burrows or vacant territories. The density of consumable resources such as seeds could not change significantly during the brief period the populations were depressed. Access to food, however, would have changed if these rodents are territorial or display avoidance behavior. The small size and nocturnal activity of heteromyids have discouraged direct field studies of their mutual interactions, but indirect evidence (Vorhies and Taylor, 1922; Schroder and Geluso, in prep.) indicate that adult D. spectabilis live a solitary existence. Laboratory studies in which encounters were observed in small enclosures (Christopher, 1973; Eisenberg, 1963; Smige1, pers comm.) reveal various high levels of agonistic behavior between both congeners and conspecifics.

Eisenberg (1963) concluded that the stereotyped behavior he observed in several species of Dipodomys had 

evolved to adapt these species to life in an arid environment. In encounters between members of the same species, mutual avoidance and agonistic behaviors predominated unless one individual was a female in estrus. Physical contact was the exception rather than the rule in all encounters. He postulated that, in spite of their solitary nature, Dipodomys may have a well integrated social system in which the members may establish familiarity, not through aggressive encounters or territorial defense, but by o1factory communication at preferred sandbathing loci.

Certainly it would be highly advantageous for seed-gathering species in an arid, unproductive environment to maintain their density at an appropriate level with a minimum amount of time diverted from foraging activities. The speed with which both species recovered from perturbations strongly suggests that they may employ a refined form of intraspecific territoriality such as Eisenberg describes. 



\section{APPENDIX}

Although use of the Lincoln Index is widely accepted as an effective means of censusing small mammals, good estimates of the density of unenclosed populations still rely on knowledge of the area trapped by the grid. Traps on the periphery of the pattern are more accessible to animals from outside the grid and may, therefore, be trapping a larger area than traps nearer the center. Several methods have been used to estimate this "edge effect". Chew and Butterworth (1964) estimated that the area trapped by their grid included a peripheral border half the mean adjusted home range in width. The adjusted home range width for each individual rodent equaled the maximum distance between points of capture plus the distance between trap stations. Koplin and Hoffman (1968) determined the area censused with their grids by adding to the area enclosed by the traps, a border whose width equaled the average distance between successive points of capture for each species of vole. However, if individuals are repeatedly captured in the same trap, as is often the case with heteromyids, the average would be very low, and the effective radius of the peripheral traps would be underestimated. This method requires that the trap interval be carefully selected. Stickel (1954) and V́an Vleck (1969) review the errors and limitations of home range studies based on trapping records, and many of these 

problems apply to estimations of the area censused by unenclosed grids as well.

The method devised to estimate the density of Dipodomys' populations in this study does not require information relating to home range or movement of individual animals. Instead, it assumes that when traps are arranged in concentric, geometric arrays, such as concentric hexagons, all traps located on each hexagon have the same probability of capturing an animal, and since traps on the periphery are accessible to more animals than those in the center, the edge effect can be estimated by comparing the success of inner and outer hexagons.

Although a circle or any equilateral polygon should work, an equilateral hexagon proved to be most suitable for this study because its favorable area to edge relationship reduces the relative edge effect, and trap sites can be linearly arranged and numbered. Each grid consisted of traps arranged in 10 concentric hexagons (rows) with a 25 meter interval between traps on the same row and between traps on adjacent rows.

Selecting the proper trap interval is critically important in long term studies on large plots. Much time and effort can be saved if good population estimates can be made using a minimal number of traps. The adequacy of any trap interval can be accurately determined when traps are concentrically arranged. One begins with what intuitively 

or empirically seems to be a suitable interval. The success of traps arranged concentrically at this distance provides the data needed to refine the interval. If the animals are not clumped relative to grid size or location, then all traps on the same row (hexagon) have equal probability of catching an animal, and a ratio of the percent captures to the percent traps can be calculated for each row as follows:

$$
R_{i}=\frac{c_{i} / C}{t_{i} / T}
$$

where $c_{i}$ is the number of captures made by all traps in row $i, \underline{C}$ is total captures, $t_{i}$ is the number of traps on row $i$, and $T$ is the total number of traps on the grid.

This ratio of percentages is the means by which the trapping success of the rows are compared. If the traps are spaced at too great an interval there would be inadequate traps to obtain a reasonable census; none of the traps will compete with each other for animals, and the row ratios will all be near one. As the trap interval is shortened the density of traps increases, and traps at the periphery of the grid become accessible to more animals, on the average, than more centrally located traps. The $R_{i}$ values for the peripheral rows will become greater than 1 , and less than 1 for the central rows.

The four hypothetical curves drawn in Figure 7 illustrate how $R_{i}$ values night change as the trap interval is changed. The shortest trap interval (curve d) shows the 


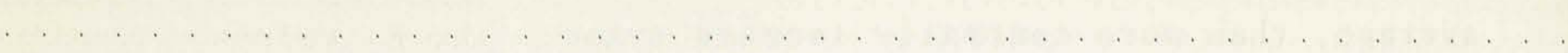


greatest difference in efficiency between inner and outer rows, whereas, the greatest trap interval (curve a) shows equal efficiency in all rows. Spaced at interval d, traps catch the most animals but only at a high cost. in time and energy; at interval a they are too far apart to accurately census the population. Compromise intervals ( $c$ and b) would be more efficient in terms of data returned per unit effort. If the population under study, or that of trap competitors, fluctuates greatly, traps spaced at the shorter interval (c) would be the better choice, as this interval provides more traps to accommodate population increases.

After a suitable trap interval has been selected, and the shape of the row curve determined, the area trapped by the resulting grid can be estimated. Traps on the inner rows will be collecting animals from about equal radii if their $R_{i}$ values are about equal. If, for example, the $R_{i}$ values for the first 8 rows on a 10 row grid are about equal, and those of the outer two rows significantly higher, it can be reasonably assumed that the edge effect extends only two rows into the grid, and that the 8 inner rows are dividing the area they encompass equally. In this case the area of influence of each trap in the inner 8 rows would equal the area enclosed by an imaginary $8 \frac{1}{2}$ row hexagon divided by the number of traps in rows 1 to 8 . The percent of captures per trap will be equal for all traps within this area but less than that for traps on rows 9 and 10 . 


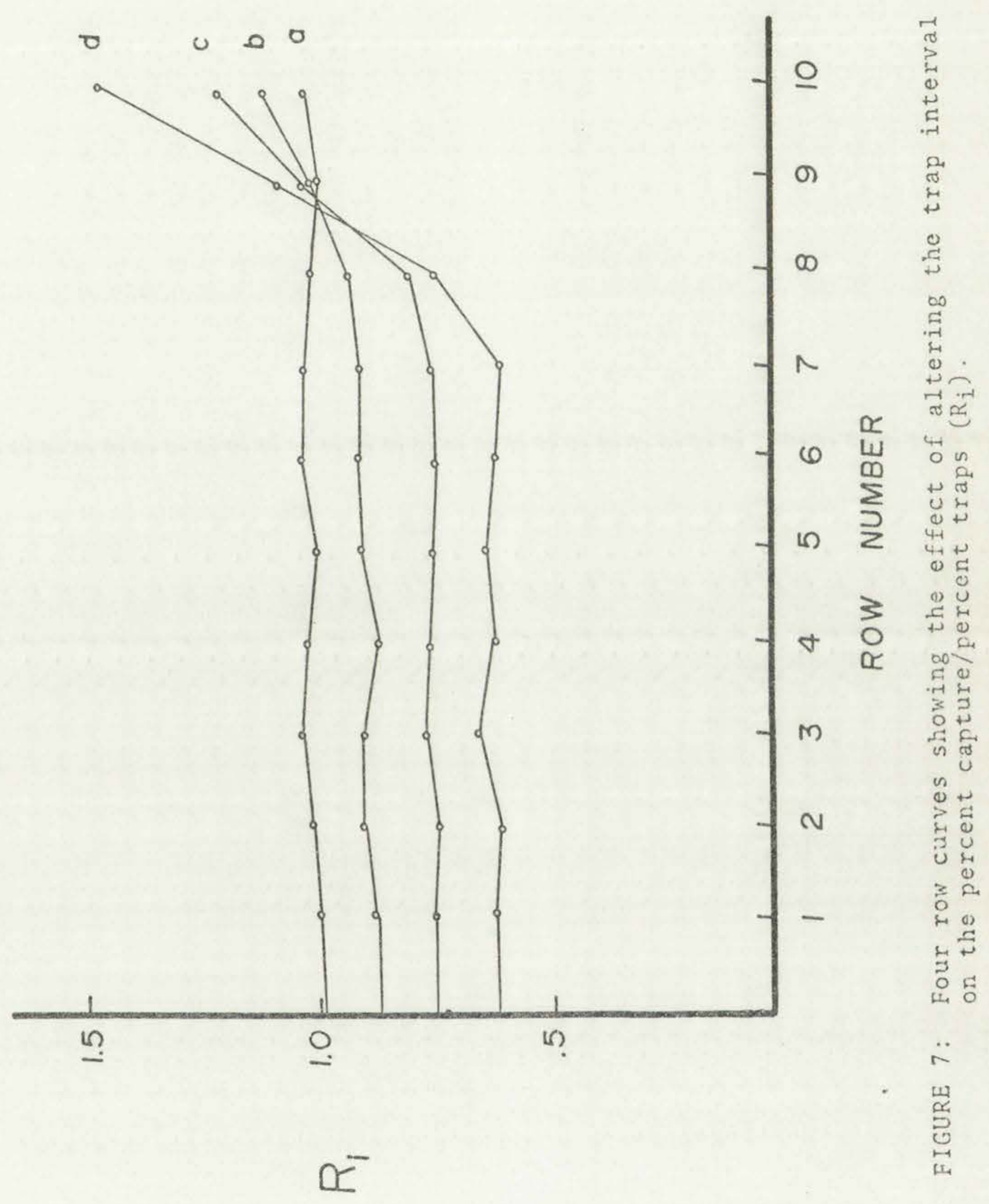



The area trapped by the outer rows is calculated as fo11ows:

$$
A_{i}=\frac{P_{i}}{\bar{P}}(a)
$$

where $\mathrm{A}_{i}$ is the area trapped by the ith outer row, $\mathrm{P}_{\mathrm{i}}$ is the percent of the total captures made on that row, $\overline{\bar{P}}$ is the average percent captures per trap for traps on the inner rows, and $\underline{a}$ is the average area trapped by each inner trap. By calculating the area trapped by peripheral rows, 9 and 10 , in this way, and adding their areas to that trapped by the inner 8 rows, the total area trapped by the 10 row grid can be estimated.

In Table 5 the Dipodomys captures from the 5 ecotonal grids are broken down by rows. There is much variation between grids, and the $\mathrm{R}_{i}$ values for the row totals from the combined grids show a pattern not predicted by the model. Although the $R_{i}$ values for rows 2 thru 10 agree reasonably well with the model, the center traps (row 0 ) and the first row traps captured more than they should if the assumptions of this technique are met. It is possible that, by chance, the grids were positioned such that many of the centers fell within an area of high Dipodomys' density, and that the relatively few trap nights represented by row 0 and row 1 provided too small a sample size to cancel this bias. Since an outer hexagon is composed of more traps, its larger sample size tends to cancel out such variation. The fact that four of the 10 grids in this study had $R_{0}$ values 


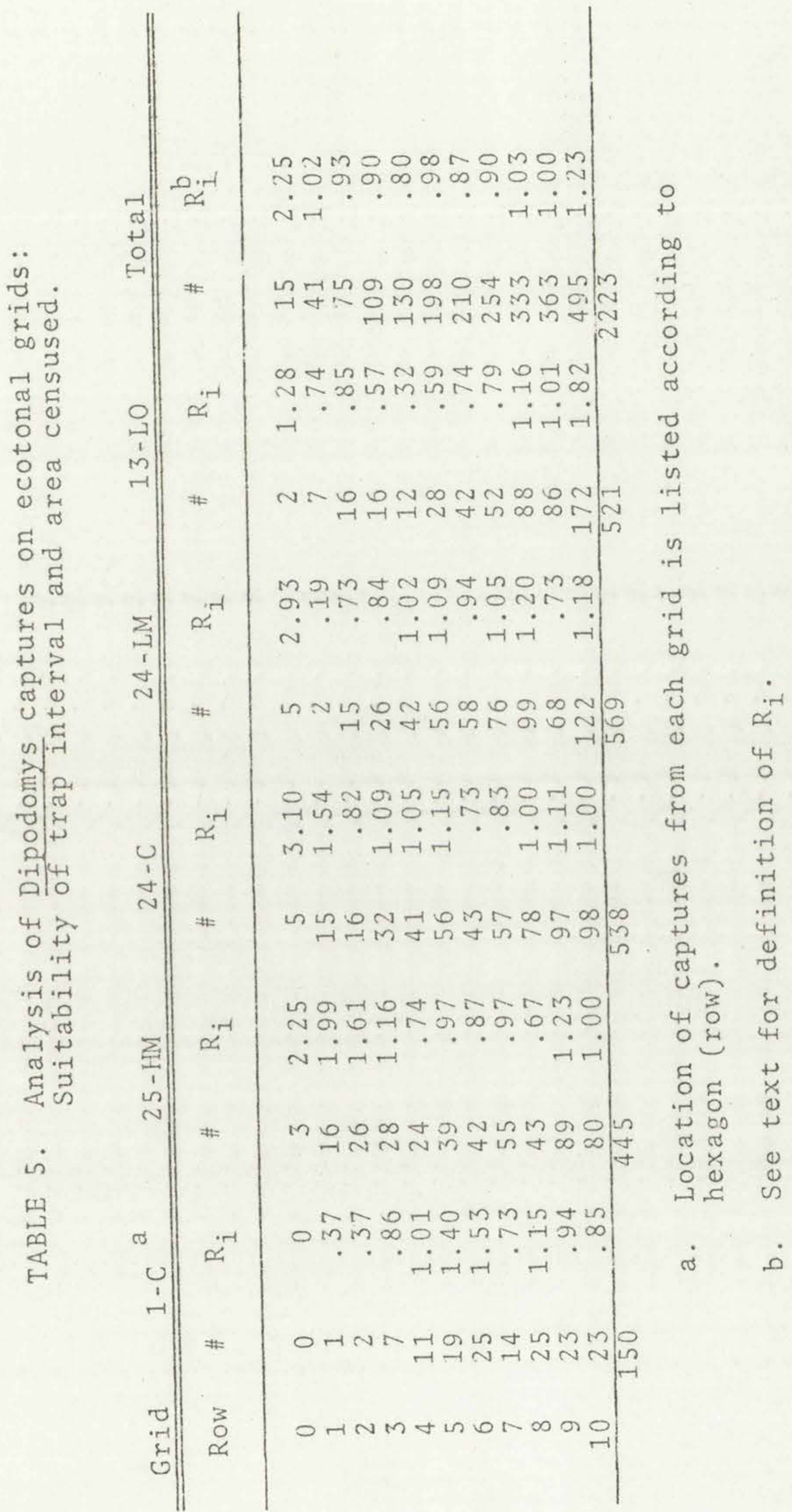



of zero tends to support this explanation.

A new row curve was made for each plot every time it was censused to determine the adequacy of the trap density as the size of the rodent populations fluctuated. In addition grid 1 -C was rotated $12 \frac{1}{2} \mathrm{~m}$ ( $\frac{1}{2}$ trap interval) and its captures resulted in censuses which were almost identical to those gathered the previous night with traps located in their normal position. This supports my belief that the grids were accurately censusing the populations.

The area formula can be applied to the combined data for each row (last column Table 5) to determine the average area trapped by each of these grids. The edge effect appears to have involved the outer three rows. The average percent captures per trap for the inner seven rows $(\bar{P})$ is .275 .

$$
\bar{p}=\frac{1032}{2223} \div 169 \times 100=.275 \% / \text { trap }
$$

and the average area trapped by each trap within a $7 \frac{1}{2}$ row hexagon is $540.44 \mathrm{~m}^{2}$.

$$
a=\frac{2.598 \times r^{2}}{\# \operatorname{traps}}=\frac{2.598\left(25 \mathrm{~m} \times 7 \frac{1}{2}\right)^{2}}{169}=540.44 \mathrm{~m}^{2} / \text { trap }
$$

The percent of the total captures made on the outer rows are: $\mathrm{P}_{8}=14.98 \%, \mathrm{P}_{9}=16.33 \%$, and $\mathrm{P}_{10}=22.27 \%$.

$$
\begin{array}{ll}
A_{7 \frac{1}{2}}=2.598\left(25 \mathrm{~m} \times 7 \frac{1}{2}\right) & =9.13 \mathrm{ha} . \\
A_{8}=14.98 / .275(540.44) & =2.94 \mathrm{ha} . \\
A_{9} & =3.21 \mathrm{ha} . \\
A_{10} & =4.38 \mathrm{ha} . \\
A_{T} & =19.66 \mathrm{ha} .
\end{array}
$$



Thus each of these five grids effectively trapped about 48.6 acres (19.66 ha.). 



\section{LITERATURE CITED}

Brown, J. H. 1973. Species diversity of seed-eating desert rodents in sand dune habitats. Ecology, 54: $775-787$.

Brown, J. H. and G.A. Lieberman 1973. Resource utilization and coexistence of seed-eating desert rodents in sand dune habitats. Ecology, 54: 787-797.

Christopher, E. A. 1973. Sympatric relationships of the kangaroo rats, Dipodomys merriami and Dipodomys agilis. J. Mamm., 54: 317-326.

Dunham, M. 1968. A comparative food habitat study of two species of kangaroo rats, Dipodomys ordii and Dipodomys merriami. Master's Thesis, University of New Mexico.

Eisenberg, J. F. 1963. The behavior of heteromyid rodents, Univ. California Pub1. Zoo1., 69: 1-114,

Grant, P. R. 1972. Interspecific competition among rodents. Ann. Rev. Ecol. Syst. 3; 79-106.

Hoffmeister, D. F. and W. Goodpaster 1954. The mamma1s of the Huachuca Mountains, southeastern Arizona. I11. Biol. Monogr. 24: 1-152.

Levins, R. 1968. Evolution in changing environments. Princeton Univ. Press, Princeton. $120 \mathrm{p}$.

MacArthur, R. H. 1972. Geographical ecology. Harper and Row, New York, 269 p.

MacArthur, R. H. and R. Levins 1964. Competition, habitat selection and character displacement in a patchy environment. Proc. Nat. Acad. Sci. 51: 12071210 .

Miller, R. S. 1967. Patterns and process in competition. Advances in ecological research (Ed. by J. B. Cragg) 4: 1-74, Academic Press, London.

Rosenzweig, M. L. 1970. p. 295 in Dynamics of populations. (Ed. by P. J. den boer and G. R. Gradwell) Center Agri. Pub. and Doc., Wageningen, 1971.

Rosenzweig, M. L. 1973. Habitat selection experiments with a pair of coexisting heteromyid rodent species. Ecology 54: 111-117. 

Rosenzweig, M. L., B. Smigel and A. Kraft. Patterns of food, space and diversity in Rodents in desert environments. (Ed. by Parkash and Gosh), Monogr. Biol., Junk, W. V., the Hague, in press.

Schroder, G. D. and K. N. Geluso. Spacial distribution of Dipodomys spectabilis mounds. in prep.

Smigel, B. W. and M. L. Rosenzweig. 1974. Experimental tests for seed size selection and allocation by Dipodomys merriami and Perognathus pennicillatus. Ecology 55 : (in press).

Sticke1, L. F. 1954. A comparison of certain methods of measuring ranges of small ammmals. J. Mamm., 35 : 1-15.

Van Vleck, D. B. 1969. Standardization of Microtus home range calculation. J. Mamm., 50:

Vorhies, C. T. and W. P. Taylor. 1922. Life history of the kangaroo rat, Dipodomys s. spectabilis. USDA. Bu11. 1091, 40 p. 



\section{CURRICULUM VITAE}

Gene David Schroder

PERSONAL DATA:

Birthdate: 25 October, 1944

Birthplace: Atascadero, California

Citizen: USA

Marital Status: Married

ACADEMIC BACKGROUND :

B.A. Rice University May 1967 Major-Biology

M.A. Rice University May 1970 Major-Ecology

Thesis title: Effects of food and density on growth, reproduction, and survivorship of Australorbis glabratus.

State University of New York at Albany August 1969 - August 1971 Major-Limnology

Ph.D. Universiy of New Mexico

$$
\begin{gathered}
\text { May } 1974 \text { Major-Population } \\
\text { Biology }
\end{gathered}
$$

TEACHING EXPERIENCE:

Teaching assistant in the following courses:

General Biology

General Physiology

Invertebrate Physiology

Human Anatomy and Physiology

Ecology

FIELDS OF SPECIAL INTEREST:

Measurements of competitive interactions.

Strategies of competition and predation.

Computer simulation of population interactions. 


